\title{
BMJ Open Association between blood lead level and risk of stroke in Korean adults: a cross-sectional study in the Korea National Health and Nutrition Examination Survey 2008-2013
}

\author{
Minkyeong Kim, Sang-Moon Yun, Jihyun Jeong, Chulman Jo, Young Ho Koh
}

To cite: Kim M, Yun S-M, Jeong J, et al. Association between blood lead level and risk of stroke in Korean adults: a cross-sectional study in the Korea National Health and Nutrition Examination Survey 2008-2013. BMJ Open 2020;10:e035725. doi:10.1136/ bmjopen-2019-035725

- Prepublication history for this paper is available online. To view these files, please visit the journal online (http://dx.doi. org/10.1136/bmjopen-2019035725).

Received 13 November 2019 Revised 20 July 2020 Accepted 05 August 2020

\section{Check for updates}

(c) Author(s) (or their employer(s)) 2020. Re-use permitted under CC BY-NC. No commercial re-use. See rights and permissions. Published by BMJ.

Division of Brain Diseases, Korea National Institute of Health, Cheongju, South Korea

Correspondence to Dr Young Ho Koh; kohyoungh0122@gmail.com

\section{ABSTRACT}

Objectives Although lead is a potential risk factor for cardiovascular diseases such as stroke, research on this association in the Korean population remains limited. Therefore, we aimed to investigate the association between lead level and stroke in Korean adults. Design A population-based cross-sectional study. Setting The Korea National Health and Nutrition Examination Survey 2008-2013, which enrolled a representative sample of the Korean population. Participants We excluded participants younger than 20 years, missing weight data, pregnant or lactating, and missing blood lead and stroke data. A total of 11510 participants were included in this analysis.

Primary and secondary outcome measurement The participants were classified by blood lead concentration into the low-level $(\leq 2.189 \mu \mathrm{g} / \mathrm{dL}, \mathrm{n}=5756)$ and high-level $(>2.189 \mu \mathrm{g} / \mathrm{dL}, \mathrm{n}=5754)$ groups. The main outcome, stroke, was assessed by information from physician diagnosis, prevalence of stroke or treatment for stroke. The ORs and 95\% Cls were calculated to evaluate the association between blood lead level and stroke using multivariate logistic regression analysis.

Results Although blood lead level was not significantly associated with stroke (OR: $1.30,95 \% \mathrm{Cl}$ : 0.66-2.58) in the multivariate-adjusted model, in individuals with hypertension, the high-level group was 2.36-fold higher odds of stroke (OR: $2.36,95 \% \mathrm{Cl}: 1.02-5.44)$ compared to that in the low-level group. No association was observed in individuals with normotension (OR: $0.42,95 \% \mathrm{Cl}: 0.13-$ 1.38, $\mathrm{p}$ for interaction $=0.007$ ).

Conclusion The association between blood lead concentration and stroke may be influenced by hypertension status. Our findings suggest the need for closer attention to lead exposure in patients with hypertension.

\section{INTRODUCTION}

Stroke is the second cause of death worldwide. ${ }^{1}$ The WHO Global Health Estimates reported in 2016 that stroke accounted for $10.2 \%$ of total deaths and was the leading cause of death in the past 15 years. ${ }^{12}$ Statistics
Strengths and limitations of this study

- This study used data from the Korea National Health and Nutrition Examination Survey, which is nationally representative of the non-institutionalised civilians in Korea.

- The association between blood lead and stroke adjusted for various factors including preceding diseases was investigated.

- A causal relationship between blood lead and stroke not clearly obtained because of the cross-sectional study.

- The possibility of presence of residual confounding factors remains, as the observational study.

Korea reported that mortality caused by stroke was fourth highest among causes of death in $2018 .^{3}$ Stroke is a leading cause of the functional disorder. Previous studies have reported that the risk of disability increased after stroke. ${ }^{45}$ In addition, the risk of disability by stroke was higher than myocardial infarction. ${ }^{4}$ The prevalence of stroke leads to poor quality of life, ${ }^{67}$ economic burden from medical expense, ${ }^{8}$ and high burden of disease ${ }^{9}$ and disability. ${ }^{10}$ Ultimately, it negatively affects both countries and individuals. Therefore, the primary prevention of stroke, which is a high proportion of first onset ${ }^{11}$ is important.

Lead is a risk factor for cardiovascular disease such as stroke ${ }^{12}$ and is widely distributed in gasoline, paint, air pollution, and soil pollution. ${ }^{1314}$ The health problems associated with short-term and long-term lead exposure affect the haematological and nervous systems, kidney function and cardiovascular system. ${ }^{13} 15$ The reference value for blood lead level was established at $10 \mu \mathrm{g} / \mathrm{dL}$, some agencies, including the Centers for Disease Control and Prevention (CDC), recently 
defined $5 \mu \mathrm{g} / \mathrm{dL}$ as the reference blood lead level for adults in the USA. ${ }^{16}{ }^{17}$ According to previous studies, both low and high lead concentrations have negative cardiovascular effects. ${ }^{18-23}$ The cohort study of the National Health and Nutrition Examination Survey (NHANES) showed a dose-response relationship between blood lead level and mortality due to stroke (HR: 2.51, 95\% CI: $1.20-5.26$, p for trend $=0.017) .{ }^{18}$ Furthermore, a meta-analysis that pooled estimates of relative risk (RR) reported a 1.63-fold increased risk of stroke in individuals with elevated blood lead levels (RR: 1.63, 95\% CI: 1.14-2.34). ${ }^{24}$ Finally, a crosssectional study in Korean adults that stratified analysis by sex observed a positive association in women (OR: 1.44, 95\% CI: 1.09-1.92), but not in men. ${ }^{25}$

Until now, few studies have assessed the association between lead and stroke in the Korean population. Preceding diseases such as hypertension, dyslipidaemia and diabetes have been associated with $\operatorname{lead}^{26-28}$ and are risk factors for stroke. ${ }^{29}{ }^{30}$ However, previous studies were not adequately controlled for potential confounding factors such as preceding diseases. ${ }^{25}$ Therefore, we aimed to investigate the association between blood lead level and stroke considering the effects of preceding diseases in Korean adults.

\section{METHODS}

\section{Study population}

This study as a cross-sectional analysis was conducted using data from the Korea National Health and Nutrition Examination Survey (KNHANES), which was a nationally representative data. ${ }^{31}$ The nationwide KNHANES recruited participants from the Korean population. The survey enrolled a representative sample of the noninstitutionalised Korean population and was performed using a complex sampling design.

Of the 53829 individuals who participated in the KNHANES 2008-2013, we excluded those who were (1) younger than 20 years $(\mathrm{N}=13501)$, (2) missing weight data $(\mathrm{N}=28400)$, (3) pregnant or lactating $(\mathrm{N}=178)$ and (4) missing blood lead and stroke data $(\mathrm{N}=240)$. Finally, we included 11510 participants in the present study (figure 1).

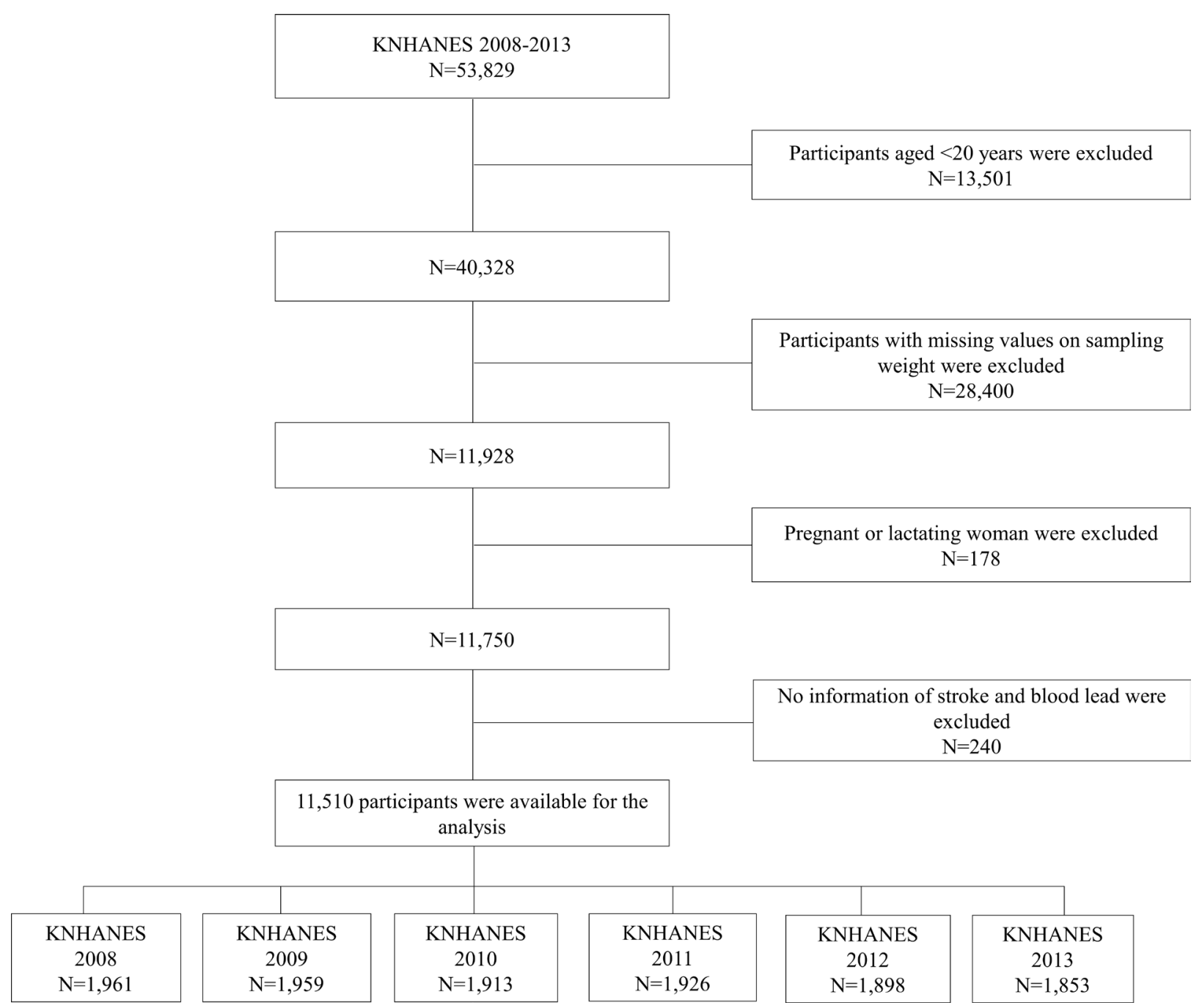

Figure 1 Flow diagram of present study. KNHANES, Korea National Health and Nutrition Examination Survey. 
Written informed consent was obtained from all participants and the KNHANES data sets which had available data in our study were approved by the Institutional Review Board (IRB) of the Korea CDC (KCDC) (IRB numbers: 2008-04EXP-01-C, 2009-01CON-03-2C, 2010-02CON-21-C, 2011-02CON-06-C, 2012-01EXP-01-2C, 2013-07CON-03-4C and 2013-12EXP-03-5C).

\section{General characteristics}

The demographic characteristic and lifestyle information included age, sex, education level, household income level, smoking status, alcohol consumption, physical activity and family history of stroke, which were obtained from the health interview and health examination. Education level was categorised as less than high school graduation and high school graduation or more. Household income level was divided into low, mid-low, mid-high and high groups. Smoking status was categorised as former or current smoker and non-smoker. Alcohol consumption was computed by multiplying the quantity of alcohol consumed by the daily frequency of consumption. Physical activity was defined as metabolic equivalents of task (MET-hour/week) and was classified as follows: low, $<20$ METs-hour/week; middle, 20-<40 METs-hour/week; high, $\geq 40$ METs-hour/week. Family history of stroke was obtained from the health examination and defined as having at least one parent with diagnosed stroke.

\section{Measurement of blood lead concentration}

Blood heavy metal concentrations were measured part of the total examined group in KNHANES and was conducted in the Neodin Medical Institute. Blood lead concentration was measured by graphite furnace atomic absorption spectrometry with Zeeman background correction using a PerkinElmer AAnalyst 600 instruments (PerkinElmer, Finland).

\section{Definition of disease}

Obesity status was classified as underweight or normal $\left(<23 \mathrm{~kg} / \mathrm{m}^{2}\right)$ or overweight or obese $\left(\geq 23 \mathrm{~kg} / \mathrm{m}^{2}\right)$ according to the body mass index criteria for Asian populations from the $\mathrm{WHO}^{32}$ Hypertension was defined as those with systolic blood pressure $\geq 140 \mathrm{~mm} \mathrm{Hg}$ or diastolic blood pressure $\geq 90 \mathrm{~mm} \mathrm{Hg}$, antihypertensive medicine use or physician diagnosis of hypertension. Dyslipidaemia was defined as having at least one of the following criteria: ${ }^{33}$ (1) hypercholesterolaemia: total cholesterol $\geq 240 \mathrm{mg} /$ dL or use of lipid-lowering agents; (2) hypo-high density lipoprotein (HDL) cholesterolaemia: HDL cholesterol $<40 \mathrm{mg} / \mathrm{dL}$; (3) hypertriglyceridaemia: triglyceride $\geq 200 \mathrm{mg} / \mathrm{dL}$ ); (4) hyper-low density lipoprotein (LDL) cholesterolaemia: LDL cholesterol $\geq 160 \mathrm{mg} / \mathrm{dL}$ or use of lipid-lowering agents or (5) physician diagnosis of dyslipidaemia. Diabetes mellitus was defined as fasting plasma glucose level $\geq 126 \mathrm{mg} / \mathrm{dL},{ }^{34}$ diabetes treatments (insulin injection or oral hypoglycaemic agent) or physician diagnosis of diabetes. Stroke, the main outcome, was defined as physician diagnosis, current presence of stroke or treatment for stroke.

\section{Statistical analysis}

Statistical analyses considered the multistage, stratified and clustered probability sampling design using SURVEY procedures in SAS (Statistical Analysis System V.9.4). Based on their median blood lead concentrations, the participants were categorised into the low-level $(\leq 2.189 \mu \mathrm{g} / \mathrm{dL})$ or high-level $(>2.189 \mu \mathrm{g} / \mathrm{dL})$ group. The general characteristics were compared according to these groups and are presented as frequencies and percentage or means and SDs. The differences between the two groups were assessed by $\chi^{2}$ tests and general linear regression analysis. Multivariable logistic regression analysis was used to calculate the ORs and 95\% CIs for the association between blood lead level and prevalent stroke. The potential confounding factors were determined through preliminary analysis and literature review ${ }^{18192535}$ and were adjusted as four models: (1) model 1: unadjusted; (2) model 2: adjusted for age, sex and body mass index; (3) model 3: additionally adjusted for education level, household income level, smoking status, alcohol consumption and physical activity; and (4) model 4: additionally adjusted for family history of stroke, dyslipidaemia and diabetes mellitus. The effect modifiers were confirmed using multiplicative terms in the fully adjusted model (model 4). Missing values for confounding factors were excluded from these analyses. All statistical analyses were performed using SAS V. 9.4 and statistical significance set at $\alpha=0.05$.

\section{Patient and public involvement}

The KNHANES raw data were provided except personal identification information. The design of this research was done without the study population involvement.

\section{RESULTS}

The mean blood lead concentration of overall participants was $2.39 \pm 1.18 \mu \mathrm{g} / \mathrm{dL}$. The general characteristics of the participants according to blood lead level are shown in table 1. The average blood lead concentrations of the low-level and high-level groups were $1.59 \pm 0.38$ and $3.18 \pm 1.18 \mu \mathrm{g} / \mathrm{dL}$, respectively. Higher blood lead concentrations $(>2.189 \mu \mathrm{g} / \mathrm{dL})$ were observed for men $(\mathrm{p}<0.001)$, older participants $(p<0.001)$, smokers $(p<0.001)$, higher alcohol consumption $(\mathrm{p}<0.001)$, higher physical activity $(\mathrm{p}<0.001)$, overweight or obese $(\mathrm{p}<0.001)$ and high rate of family history of stroke $(p<0.001)$. Furthermore, the proportions of participants with hypertension $(\mathrm{p}<0.001)$, dyslipidaemia $(p<0.001)$ and diabetes mellitus $(p<0.001)$ were higher in the high-level group than in the low-level group. Participants with lower blood lead concentration $(\leq 2.189 \mu \mathrm{g} / \mathrm{dL})$ had significantly higher household income $(\mathrm{p}=0.002)$ and education level $(\mathrm{p}<0.001)$.

Table 2 presents the ORs and $95 \%$ CIs of the associations between blood lead level and stroke. In the unadjusted 
Table 1 General characteristics according to blood lead, KNHANES 2008-2013 $(n=11510)$

\begin{tabular}{|c|c|c|c|}
\hline & \multicolumn{2}{|c|}{ Blood lead levels } & \multirow[b]{2}{*}{$P$ value } \\
\hline & $\begin{array}{l}\text { Low } \\
\text { ( } \leq 2.189 \mu \mathrm{g} / \\
\mathrm{dL})\end{array}$ & $\begin{array}{l}\text { High } \\
(>2.189 \mu \mathrm{g} / \\
\mathrm{dL})\end{array}$ & \\
\hline $\begin{array}{l}\text { Number of } \\
\text { participants }\end{array}$ & 5756 & 5754 & \\
\hline Blood lead ( $\mu \mathrm{g} / \mathrm{dL})$ & $1.59 \pm 0.38$ & $3.18 \pm 1.18$ & \\
\hline Age (years) & $41.20 \pm 14.95$ & $49.71 \pm 13.62$ & $<0.001$ \\
\hline Sex (women) & $3756(65.25)$ & 1976 (34.34) & $<0.001$ \\
\hline Household income & & & 0.002 \\
\hline Low & $1392(24.43)$ & 1519 (26.74) & \\
\hline Mid-low & $1392(24.43)$ & 1451 (25.55) & \\
\hline Mid-high & $1437(25.22)$ & 1358 (23.91) & \\
\hline High & $1476(25.91)$ & $1352(23.80)$ & \\
\hline Education level & & & $<0.001$ \\
\hline $\begin{array}{l}\text { Less than high } \\
\text { school graduation }\end{array}$ & $1248(21.71)$ & $2146(37.37)$ & \\
\hline $\begin{array}{l}\text { High school } \\
\text { graduation or more }\end{array}$ & $4500(78.29)$ & 3596 (62.63) & \\
\hline Smoking status & & & $<0.001$ \\
\hline Non-smoker & 3894 (67.72) & 2335 (40.66) & \\
\hline $\begin{array}{l}\text { Former or current } \\
\text { smoker }\end{array}$ & $1856(32.28)$ & 3408 (59.34) & \\
\hline $\begin{array}{l}\text { Alcohol consumption } \\
\text { (cup/day) }\end{array}$ & $0.54 \pm 1.17$ & $1.31 \pm 1.96$ & $<0.001$ \\
\hline Obesity status & & & $<0.001$ \\
\hline $\begin{array}{l}\text { Underweight/ } \\
\text { normal }\end{array}$ & $2871(49.97)$ & $2183(38.08)$ & \\
\hline Overweight/obese & $2875(50.03)$ & 3550 (61.92) & \\
\hline Physical activity* & & & $<0.001$ \\
\hline Low & 2959 (51.49) & 2582 (44.99) & \\
\hline Middle & $1154(20.08)$ & 1068 (18.61) & \\
\hline High & $1634(28.43)$ & $2089(36.40)$ & \\
\hline $\begin{array}{l}\text { Family history of } \\
\text { stroke (yes) }\end{array}$ & $345(9.05)$ & $392(12.17)$ & $<0.001$ \\
\hline \multicolumn{4}{|l|}{ History of disease (yes) } \\
\hline Hypertension & $1097(19.06)$ & $1871(32.52)$ & $<0.001$ \\
\hline Diabetes mellitus & $434(7.67)$ & $551(9.80)$ & $<0.001$ \\
\hline Dyslipidaemia & 1630 (28.32) & $2210(38.41)$ & $<0.001$ \\
\hline
\end{tabular}

Values are $\mathrm{n}(\%)$ or mean $\pm \mathrm{SD}$.

*Physical activity was categorised as follows: low, <20 METs-hour/ week; middle, 20-<40 METs-hour/week; high, $\geq 40$ METs-hour/ week.

KNHANES, Korea National Health and Nutrition Examination Survey; MET, metabolic equivalents of task.

model (model 1), we observed that the high-level group $(>2.189 \mu \mathrm{g} / \mathrm{dL})$ had higher odds of stroke than the lowlevel group $(\leq 2.189 \mu \mathrm{g} / \mathrm{dL}) \quad$ (OR: $1.84,95 \%$ CI: $1.19-$ 2.85). However, in the fully adjusted model (model 4),
Table 2 The OR of stroke and $95 \% \mathrm{Cl}$ according to blood lead $(n=11510)$

\begin{tabular}{ll} 
Blood lead levels \\
\hline Low & High \\
$(\leq 2.189 \mu \mathrm{g} / \mathrm{dL})$ & $(>2.189 \mu \mathrm{g} / \mathrm{dL})$ \\
\hline OR & OR $(95 \% \mathrm{Cl})$
\end{tabular}

\begin{tabular}{lrl}
\hline Stroke & & \\
No. of cases & 60 & 114 \\
\hline Model 1 & 1 & $1.84(1.19-2.85)$ \\
\hline Model 2 & 1 & $1.09(0.67-1.76)$ \\
\hline Model 3 & 1 & $1.03(0.63-1.67)$ \\
\hline Model 4 & 1 & $1.30(0.66-2.58)$ \\
\hline
\end{tabular}

Model 1: unadjusted.

Model 2: adjustment for age, sex and body mass index.

Model 3: model 2 plus additional adjustments for education level, household income level, smoking status, alcohol consumption and physical activity.

Model 4: model 3 plus additional adjustments for family history of stroke, dyslipidaemia and diabetes mellitus.

the blood lead level was not significantly associated with the stroke (OR: $1.30,95 \%$ CI: 0.66-2.58).

Our study found that hypertension was an effect modifier ( $p$ for interaction=0.007) and conducted a stratified analysis according to hypertension status (table 3). This association was significant among participants with hypertension, and the high-level group had 2.36-fold higher odds of stroke $(>2.189 \mu \mathrm{g} / \mathrm{dL}$; OR: 2.36 , 95\% CI: $1.02-$ $5.44)$ compared with the low-level group $(\leq 2.189 \mu \mathrm{g} /$ $\mathrm{dL}$ ). No association between blood lead and stroke was observed in participants with normal blood pressure (OR: 0.42, 95\% CI: 0.13-1.38).

\section{DISCUSSION}

The present study examined the association between blood lead level and stroke in Korean adults using data from the KNHANES 2008-2013. The results showed that blood lead levels were not significantly associated with stroke. However, among participants with hypertension, higher blood lead concentrations were associated with the higher risk of prevalent stroke compared with lower blood lead levels.

Lead, as an environmental toxic metal, is ubiquitous in the environment. The sources of lead exposure in the general population are well known gasoline, paint, food, air pollutants and soil pollution. ${ }^{14} 3637$ Previous studies reported that blood lead concentration was associated with smoking and alcohol drinking. ${ }^{38}$ Also, air pollutants considered a source of lead exposure. The particulate matter (PM) among air pollutants contains complex mixture consists of organic carbon, metal including lead and cadmium. ${ }^{40}{ }^{41}$ Lead within the airborne PM can enter and accumulate the body through the airborne PM. In Canada, the main source of lead exposure is food. ${ }^{42}$ Moreover, water, dust, paint, soil and lead-contaminated 
Table 3 The OR of stroke and $95 \% \mathrm{Cl}$ according to blood lead, stratified by hypertension status $(n=11510)$

\begin{tabular}{|c|c|c|c|}
\hline & \multicolumn{2}{|c|}{ Blood lead levels } & \multirow{3}{*}{$\begin{array}{l}\mathbf{P} \text { for } \\
\text { interaction }\end{array}$} \\
\hline & \multirow{2}{*}{$\begin{array}{l}\text { Low } \\
(\leq 2.189 \mu \mathrm{g} / \mathrm{dL}) \\
\text { OR }\end{array}$} & \multirow{2}{*}{$\begin{array}{l}\text { High } \\
(>2.189 \mu \mathrm{g} / \mathrm{dL}) \\
\text { OR }(95 \% \mathrm{Cl})\end{array}$} & \\
\hline & & & \\
\hline \multicolumn{3}{|c|}{ Hypertension } & 0.007 \\
\hline $\begin{array}{l}\text { No. of } \\
\text { cases }\end{array}$ & 39 & 85 & \\
\hline Model 1 & 1 & $1.45(0.86-2.47)$ & \\
\hline Model 2 & 1 & $1.39(0.77-2.50)$ & \\
\hline Model 3 & 1 & $1.36(0.75-2.47)$ & \\
\hline Model 4 & 1 & $2.36(1.02-5.44)$ & \\
\hline \multicolumn{4}{|c|}{ Non-hypertension } \\
\hline $\begin{array}{l}\text { No. of } \\
\text { cases }\end{array}$ & 21 & 29 & \\
\hline Model 1 & 1 & $1.31(0.62-2.74)$ & \\
\hline Model 2 & 1 & $0.59(0.27-1.30)$ & \\
\hline Model 3 & 1 & $0.60(0.27-1.31)$ & \\
\hline Model 4 & 1 & $0.42(0.13-1.38)$ & \\
\hline
\end{tabular}

Model 1: unadjusted.

Model 2: adjustment for age, sex and body mass index. Model 3: model 2 plus additional adjustments for education level, household income level, smoking status, alcohol consumption and physical activity.

Model 4: model 3 plus additional adjustments for family history of stroke, dyslipidaemia and diabetes mellitus.

non-food products were considered a source of lead exposure. ${ }^{42}$ Other countries, such as India, Mexico and Vietnam, reported that medication and unregulated cosmetics products were a source of lead. ${ }^{36}$ In Iran, individuals working in radiator manufacturing or printing factory were associated with blood lead, ${ }^{43}$ and opium was presented as a new source of lead exposure. ${ }^{44}$ The average blood lead of the present study participants was $2.39 \pm 1.18 \mu \mathrm{g} / \mathrm{dL}$, which is lower than the reference of lead level in CDC $(5 \mu \mathrm{g} / \mathrm{dL}) .{ }^{17}$ According to the NHANES, the mean blood lead concentration was $1.82 \mu \mathrm{g} / \mathrm{dL}$ (range $0.18-33.10 \mu \mathrm{g} / \mathrm{dL}),{ }^{45}$ and the Canada Health Measures Survey reported that blood lead concentration was $1.2 \mathrm{\mu g} / \mathrm{dL}$ in aged $20-79$ years. ${ }^{46}$ The average blood lead levels for these countries were lower than in our study. Whereas, the studies were presented that the mean blood lead concentrations for German and Iran populations were $3.07 \mu \mathrm{g} / \mathrm{dL}^{47}$ and $5.11 \pm 7.41 \mu \mathrm{g} / \mathrm{dL},{ }^{48}$ respectively, and the median level for China was $4.40 \mu \mathrm{g} / \mathrm{dL},{ }^{19}$ which is relatively higher than our result.

Lead is absorbed from the respiratory or gastrointestinal tracts. ${ }^{49}$ Lead absorbed into the body accumulates primarily in bone, as well as blood or soft tissues such as the brain, kidney and liver. ${ }^{135051}$ Hence, it is known that the exposure of lead induces the toxicity in the kidney and liver. ${ }^{52-54}$ In the brain, lead results in neuronal cell death leading to memory loss and the pathogenesis of Alzheimer's disease (AD).$^{55}{ }^{56}$ In this regard, a case-control study showed that the blood lead level is increased in $\mathrm{AD}$ compared with that of healthy control (OR: $1.05,95 \%$ CI 1.01-1.09) ${ }^{56}$ Furthermore, in patients with multiple sclerosis, the blood lead level is elevated than that of healthy control (OR: 1.17, 95\% CI: 1.001-1.28, per $1 \mu \mathrm{g} / \mathrm{L}$ increment). ${ }^{57}$ Growing evidence showed that lead exposure affects cardiovascular health. ${ }^{58}{ }^{59}$ Lead exposure is associated with negative effects on cardiovascular health. The possible mechanisms to explain this association include increased oxidative stress in response to lead; ${ }^{60} 61$ elevated reactive oxygen species may oxidise nitric oxide, leading to lipid damage.$^{60}$ In addition, lead induces inflammation via activation of nuclear transcription factor- $\kappa \mathrm{B}$, which results in impairment of cerebral blood vessels. ${ }^{61}$ Finally, high blood pressure and subsequent arteriosclerosis are caused by vasomotor tone. ${ }^{12}{ }^{62}$ These mechanisms can lead to cardiovascular disease including stroke.

Until now, epidemiological studies have observed inconsistent results on the association between blood lead level and stroke. Accumulating evidence showed that the level of lead in blood is associated with cardiovascular disease, including stroke. ${ }^{18} 1959$ In a prospective cohort study on the association between blood lead concentration below $10 \mu \mathrm{g} / \mathrm{dL}$ and mortality due to stroke in the US adults, the highest tertile of blood lead had a 2.51-fold increased risk of incident mortality than that for the lowest tertile (HR: 2.51, 95\% CI: $1.20-5.26) .{ }^{18}$ The SPECT-China showed a significant association between blood lead level and the prevalence of cardiovascular disease in women (OR: 1.93, 95\% CI: $1.22-3.04$, p for trend <0.01). ${ }^{19}$ A meta-analysis that pooled estimates on the association between blood lead level and the incidence of stroke reported that blood lead increased the risk of stroke (RR: $1.63,95 \%$ CI: 1.142.34) ${ }^{59}$ Recently, a case-control study also reported that the lead in the blood is significantly associated with acute stroke (OR: 1.04, 95\% CI: $1.02-1.07$ per $1 \mu \mathrm{g} / \mathrm{dL}$ in blood lead), suggesting a risk factor for ischaemic stroke. ${ }^{63}$ Nevertheless, other studies did not observe a significant association. A prospective cohort study of the effect of blood lead on mortality due to stroke reported that the risk of stroke mortality did not differ according to blood lead level in older women (OR: 1.13, 95\% CI: 0.34-3.81). ${ }^{64}$ A case-control study showed a non-significant association between serum lead and acute ischaemic stroke (OR: $0.97,95 \%$ CI: $0.91-1.02) .{ }^{65}$ In present study, we found that blood lead was not associated with stroke.

Meanwhile, our findings indicate that hypertension status influenced the association between lead and stroke. No association was identified between blood lead level and stroke in participants with normal blood pressure; however, lead level was positively associated with prevalence of stroke in individuals with hypertension. The previous study was shown that there was a significant interaction between chronic obstructive pulmonary disease and blood lead on stroke. ${ }^{66}$ Other studies have reported hypertension to be an effect modifier of 
the association between blood lead and chronic kidney disease related to a significantly higher risk of chronic kidney disease in patients with hypertension. ${ }^{54} 67$ High blood pressure progressively damages blood vessels; ${ }^{68}$ these weakened blood vessels may be blocked and ruptured by plaques and thrombus. ${ }^{69}$ Thus, patients with hypertension have a higher risk of stroke compared with that in patients with normotension. ${ }^{69}{ }^{70}$ Lead as a heavy metal contributes to elevated blood pressure. ${ }^{6271}$ Patients with hypertension were often had high lead concentrations ${ }^{2872-74}$ and resistant hypertension was also related to high lead levels. ${ }^{75}$ Moreover, lead exposure in individuals with hypertension might contribute to the risk of stroke due to the hypertensive effects of lead, including high blood pressure and impaired blood vessels. Additional studies are required to determine the mechanism of this association.

The reference blood lead level for adults was previously set to $10 \mu \mathrm{g} / \mathrm{dL}$, but has been readjusted to $5 \mu \mathrm{g} /$ $\mathrm{dL}$ since 2015. However, we observed that those with hypertension in the group with blood lead concentration above $2.189 \mu \mathrm{g} / \mathrm{dL}$, below readjusted reference of blood lead, were associated with higher prevalence of stroke. In addition, the several studies reported that blood lead concentration as low as $2 \mu \mathrm{g} / \mathrm{dL}$ was negative effect of various diseases including hypertension and cardiovascular disease. ${ }^{18677677}$ Our result was similar to these previous studies. Further, researches on health impact of lower lead concentration than reference blood lead are required.

Our study has several limitations. First, the causality between blood lead level and stroke was not clearly determined (reverse causal relationship) due to the cross-sectional analysis. Second, while bone lead concentrations are more reflective of long-term exposure (halflife 10 years) rather than blood lead concentration (half-life 1-2 months), ${ }^{50} 73$ these data were not available in the KNHANES. Third, lead exposure by occupational and highly contaminated areas was not considered because the KNHANES data do not provide detailed information to divided lead workers and high lead exposure areas. Despite these limitations, this study sample, the KNHANES, is representative of the Korean population; thus, our results are generalisable to Korean adults. Furthermore, this study provides evidence of this association in Korean adults.

\section{CONCLUSION}

Our findings indicated that blood lead concentration was not associated with stroke. However, in participants with hypertension, blood lead level was associated with higher risk of prevalent stroke. These results suggest the potentially harmful effects of blood lead on stroke in individuals with hypertension. Large-scale prospective cohort studies are required to identify the causality between blood lead and risk of stroke.
Contributors MK conducted the analysis and wrote the draft of the manuscript. S-MY, JJ and CJ contributed to data interpretation and review of the manuscript. YHK designed and supervised the manuscript. All authors read and approved the final version.

Funding This research was supported by Centers for Disease Control and Prevention, Republic of Korea grant number (2017-NI62002-02, 2019-NI086-00).

Competing interests None declared.

Patient consent for publication Not required.

Ethics approval This study was approved by the IRB of the KCDC with approval numbers (2017-05-06-C-A).

Provenance and peer review Not commissioned; externally peer reviewed.

Data availability statement Data are available in a public, open access repository. All data used in this study are available in the Korea Centers for Disease Control and Prevention (KCDC) and KNHANES repository (https://knhanes.cdc.go.kr/ knhanes/sub03/sub03_02_02. do).

Open access This is an open access article distributed in accordance with the Creative Commons Attribution Non Commercial (CC BY-NC 4.0) license, which permits others to distribute, remix, adapt, build upon this work non-commercially, and license their derivative works on different terms, provided the original work is properly cited, appropriate credit is given, any changes made indicated, and the use is non-commercial. See: http://creativecommons.org/licenses/by-nc/4.0/.

ORCID iD

Young Ho Koh http://orcid.org/0000-0001-9934-5321

\section{REFERENCES}

1 World Health Organization. The top 10 causes of dealth. Available: https://www.who.int/news-room/fact-sheets/detail/the-top-10causes-of-death [Accessed 24 Jul 2019].

2 World Health Organization. Global health estimates 2016 summary tables: global deaths by cause, age and sex, 2000-2016. Available: https://www.who.int/healthinfo/global_burden_disease/estimates/en/

3 Statistics Korea. 2017 cause of death. Available: http://www.kostat. go.kr/portal/korea/kor_nw/3/index.board?bmode=read\&bSeq $=\&$ aSeq $=370711$ \&pageNo $=1$ \&rowNum $=10$ \&navCount $=10 \&$ currPg $=\&$ sTarget=title\&sTxt=0 [Accessed 24 Jul 2019].

4 Dhamoon MS, Longstreth WT, Bartz TM, et al. Disability trajectories before and after stroke and myocardial infarction: the cardiovascular health study. JAMA Neurol 2017;74:1439-45.

5 National Rehabilitation Center. A study on rehabilitation medical service delivery system and policy improvement. Available: http:// www.nrc.go.kr/research/board/boardView.do?no=15759\&fno=37\& depart_no=\&menu_cd=05_02_00_01\&board_id=NRC_NOTICE_ BOARD\&bn=newsView\&search item $=1 \&$ search content $=\% E C \%$ 9E\%AC\%ED\%99\%9C\%EC\%9D\%98\%EB\%A3\%8C\%20\%EC\% A0\%84\%EB\%8B\%AC\%EC\%B2\%B4\%EA\%B3\%84\%20\%EB\% B0\%8F\%20\%EC\%A0\%95\%EC\%B1\%85\%20\%EA\%B0\%9C\% EC\%84\%A0\%EB\%B0\%A9\%EC\%95\%88\%20\%EC\%97\%B0\% EA\%B5\%AC\&pagelndex $=1$

6 Chen Q, Cao C, Gong L, et al. Health related quality of life in stroke patients and risk factors associated with patients for return to work. Medicine 2019;98:e15130.

7 Jaracz K, Kozubski W. Quality of life in stroke patients. Acta Neurol Scand 2003;107:324-9.

8 Bloom DE, Chen S, Kuhn M, et al. The economic burden of chronic diseases: estimates and projections for China, Japan, and South Korea. Available: http://www.nber.org/papers/w23601 [Accessed 26 Aug 2019].

9 World Health Organization. Global health estimates 2016 summary tables: global DALYs by cause, age and sex, 2000-2016. Available: https://www.who.int/healthinfo/global_burden_disease/estimates/en/ index1.html [Accessed 29 Jul 2019].

10 Institute for Health Metrics and Evaluation. Findings from the global burden of disease study 2017. Seattle, WA: IHME, 2018.

11 Go AS, Mozaffarian D, Roger VL, et al. Heart disease and stroke statistics-2014 update: a report from the American Heart Association. Circulation 2014;129:e28-92.

12 Alissa EM, Ferns GA. Heavy metal poisoning and cardiovascular disease. J Toxicol 2011;2011:870125

13 World Health Organization. Lead poisoning and health. Available: https://www.who.int/news-room/fact-sheets/detail/lead-poisoningand-health [Accessed $30 \mathrm{Jul}$ 2019]. 
14 Abadin H, Ashizawa A, Stevens YW, et al. Agency for toxic substances and disease registry (ATSDR) toxicological profiles. toxicological profile for lead. Atlanta, GA: Agency for Toxic Substances and Disease Registry (US), 2007.

15 Mcguigan MA. Chronic poisoning: trace metals and others. In: Goldman L, Schafer Al, eds. Goldman's Cecil medicine, 2012: 88-95.

16 National Notifiable Diseases Surveillance System. Lead, elevated blood levels 2016 case definition. Available: https://wwwn.cdc.gov/ nndss/conditions/lead-elevated-blood-levels/case-definition/2016/ [Accessed 22 Aug 2019].

17 The National Institute for Occupational Safety and Health. Adult blood lead epidemiology and surveillance (ABLES). Available: https:// www.cdc.gov/niosh/topics/ables/description.html [Accessed 26 Aug 2019].

18 Menke A, Muntner P, Batuman V, et al. Blood lead below 0.48 $\mathrm{micromol} / \mathrm{L}(10 \mathrm{microg} / \mathrm{dL})$ and mortality among US adults. Circulation 2006;114:1388-94.

19 Chen C, Li Q, Nie X, et al. Association of lead exposure with cardiovascular risk factors and diseases in Chinese adults. Environ Sci Pollut Res Int 2017;24:22275-83.

20 McElvenny DM, Miller BG, MacCalman LA, et al. Mortality of a cohort of workers in Great Britain with blood lead measurements. Occup Environ Med 2015;72:625-32.

21 Xu C, Shu Y, Fu Z, et al. Associations between lead concentrations and cardiovascular risk factors in U.S. adolescents. Sci Rep 2017;7:9121

22 Yang W-Y, Staessen JA. Letter to editor: blood pressure hypertension and lead exposure. Environ Health 2018;17:16.

23 Navas-Acien A, Guallar E, Silbergeld EK, et al. Lead exposure and cardiovascular disease--a systematic review. Environ Health Perspect 2007;115:472-82.

24 Chowdhury R, Sarnat SE, Darrow L, et al. Mortality among participants in a lead surveillance program. Environ Res 2014;132:100-4.

25 Shin J-Y, Kim J-M, Kim Y. The association of heavy metals in blood, fish consumption frequency, and risk of cardiovascular diseases among Korean adults: the Korean National health and nutrition examination survey (2008-2010). Korean J Nutr 2012;45:347-61.

26 Peters JL, Kubzansky LD, lkeda A, et al. Lead concentrations in relation to multiple biomarkers of cardiovascular disease: the normative aging study. Environ Health Perspect 2012;120:361-6.

27 Gambelunghe A, Sallsten G, Borné Y, et al. Low-level exposure to lead, blood pressure, and hypertension in a population-based cohort. Environ Res 2016;149:157-63.

28 Han L, Wang X, Han R, et al. Association between blood lead level and blood pressure: an occupational population-based study in Jiangsu Province, China. PLoS One 2018;13:e0200289.

29 O’Donnell CJ, Elosua R. [Cardiovascular risk factors. Insights from Framingham heart study]. Rev Esp Cardiol 2008;61:299-310.

30 World Health Organization. Cardiovascular diseases (CVDs). Available: https://www.who.int/en/news-room/fact-sheets/detail/ cardiovascular-diseases-(cvds) [Accessed 26 Aug 2019].

31 Kweon S, Kim Y, Jang M-jin, et al. Data resource profile: the Korea National health and nutrition examination survey (KNHANES). Int $J$ Epidemiol 2014;43:69-77.

32 World Health Organization. The Asia Pacific perspective: redefining obesity and its treatment. Available: www.wpro.who.int/nutrition/ documents/./Redefiningobesity.pdf [Accessed 9 Jul 2019].

33 National Cholesterol Education Program (NCEP) Expert Panel on Detection, Evaluation, and Treatment of High Blood Cholesterol in Adults (Adult Treatment Panel III). Third report of the National cholesterol education program (NCEP) expert panel on detection, evaluation, and treatment of high blood cholesterol in adults (adult treatment panel III) final report. Circulation 2002;106:3143-421.

34 Korean Diabetes Association. Treatment guideline for diabetes. Available: http://www.diabetes.or.kr/pro/publish/guide.php?code= guide\&year_v=2019\&number $=735 \&$ mode $=v i e w$ [Accessed 26 Aug 2019].

35 Mozaffarian D, Shi P, Morris JS, et al. Mercury exposure and risk of cardiovascular disease in two U.S. cohorts. N Engl J Med 2011;364:1116-25

36 Centers for Disease Control and Prevention. Sources of lead. Available: https://www.cdc.gov/nceh/lead/prevention/sources.htm [Accessed 10 Apr 2020].

37 Rothenberg SJ, Manalo M, Jiang J, et al. Blood lead level and blood pressure during pregnancy in South central Los Angeles. Arch Environ Health 1999;54:382-9.

38 Kim HR, Youn JW, Kim YY. Effects of smoking on concentration of heavy metals in blood and clinical characteristics. Public Health Weekly Report2020;2017.
39 National Institute of Food and Drug Safety Evaluation. Follow up study on the exposure level and health effects of heavy metals. Available: http://www.ndsl.kr/ndsl/search/detail/report/reportSe archResultDetail.do?cn=TRKO201700017555 [Accessed $10 \mathrm{Apr}$ 2020].

40 Adams K, Greenbaum DS, Shaikh R, et al. Particulate matter components, sources, and health: systematic approaches to testing effects. J Air Waste Manag Assoc 2015;65:544-58.

41 Yang Y, Pun VC, Sun S, et al. Particulate matter components and health: a literature review on exposure assessment. $J$ Public Health Emerg 2018;2:14.

42 National Institute of Environmental Research. Multi-media and multipathway aggregate risk assessment(iv) -Lead (Pb). Available: http:// www.prism.go.kr/homepage/entire/retrieveEntireDetail.do;jsessionid= DA2D4D13ACF16EA8CD38EAB9A28F5243.node02?cond_research name $=\&$ cond_research_start_date $=\&$ cond_research_end_date $=\&$ research_id=1480000-201500223\&pagelndex=523\&leftMenuLevel= 160 [Accessed 10 Apr 2020].

43 Nakhaee S, Amirabadizadeh A, Nakhaee S, et al. Blood lead level risk factors and reference value derivation in a cross-sectional study of potentially lead-exposed workers in Iran. BMJ Open 2019:9:e023867.

44 Hayatbakhsh MM, Oghabian Z, Conlon E, et al. Lead poisoning among opium users in Iran: an emerging health hazard. Subst Abuse Treat Prev Policy 2017;12:43.

45 Luo J, Hendryx M. Relationship between blood cadmium, lead, and serum thyroid measures in US adults - the National Health and Nutrition Examination Survey (NHANES) 2007-2010. Int J Environ Health Res 2014;24:125-36.

46 Statistics Canada. Lead, mercury and cadmium concentrations in Canadians, 2012 and 2013. Available: https://www150.statcan.gc.ca/ n1/pub/82-625-x/2015001/article/14209-eng.htm [Accessed 10 Apr 2020].

47 Becker K, Kaus S, Krause C, et al. German environmental survey 1998 (GerES III): environmental pollutants in blood of the German population. Int J Hyg Environ Health 2002;205:297-308.

48 Nakhaee S, Amirabadizadeh A, Zarban A, et al. The reference value of blood lead level among the general adult population of eastern Iran. J Environ Sci Health A Tox Hazard Subst Environ Eng 2019;54:1287-92.

49 World Health Organization Regional Office for Europe. Air quality guidelines for Europe. Available: http://www.euro.who.int/_data/ assets/pdf_file/0020/123077/AQG2ndEd_6_7Lead.pdf [Accessed 26 Sep 2019].

50 Centers for Disease Control and Prevention. Lead. Available: https:// www.cdc.gov/biomonitoring/Lead BiomonitoringSummary.html\# [Accessed 7 Jul 2017].

51 Wani AL, Ara A, Usmani JA. Lead toxicity: a review. Interdiscip Toxicol 2015;8:55-64.

52 Nakhaee S, Amirabadizadeh A, Brent J, et al. Impact of chronic lead exposure on liver and kidney function and haematologic parameters. Basic Clin Pharmacol Toxicol 2019;124:621-8.

53 Abiola AF. Risk factors for kidney disease in disadvantaged populations - communicable diseases, environmental factors, and pollutants. In: García-García G, Agodoa LY, Norris KC, eds. Chronic kidney disease in disadvantaged populations. Cambridge, MA: Academic Press, 2017: 191-207.

54 Muntner P, He J, Vupputuri S, et al. Blood lead and chronic kidney disease in the general United States population: results from NHANES III. Kidney Int 2003;63:1044-50.

55 Vlasak T, Jordakieva G, Gnambs T, et al. Blood lead levels and cognitive functioning: a meta-analysis. Sci Total Environ 2019;668:678-84.

56 Fathabadi B, Dehghanifiroozabadi M, Aaseth J, et al. Comparison of blood lead levels in patients with Alzheimer's disease and healthy people 2018;33:541-7.

57 Dehghanifiroozabadi M, Noferesti P, Amirabadizadeh A, et al. Blood lead levels and multiple sclerosis: a case-control study. Mult Scler Relat Disord 2019;27:151-5.

58 Obeng-Gyasi E. Lead exposure and cardiovascular disease among young and middle-aged adults. Med Sci 2019;7:103.

59 Chowdhury R, Ramond A, O'Keeffe LM, et al. Environmental toxic metal contaminants and risk of cardiovascular disease: systematic review and meta-analysis. BMJ 2018;362:k3310.

60 Jomova K, Valko M. Advances in metal-induced oxidative stress and human disease. Toxicology 2011;283:65-87.

61 Nava-Ruiz C, Méndez-Armenta M, Ríos C. Lead neurotoxicity: effects on brain nitric oxide synthase. J Mol Histol 2012;43:553-63.

62 Skoczynska A, Skoczynska M. Low-level exposure to lead as a cardiovascular risk factor. In: Cardiovascular risk factors. IntechOpen, 2012 
63 Mousavi-Mirzaei SM, Khorasani EY, Amirabadizadeh A, et al. Comparison of blood lead concentrations in patients with acute ischemic stroke and healthy subjects. J Trace Elem Med Biol 2020;61:126532.

64 Khalil N, Wilson JW, Talbott EO, et al. Association of blood lead concentrations with mortality in older women: a prospective cohort study. Environ Health 2009;8:15.

65 Lin C-H, Hsu Y-T, Yen C-C, et al. Association between heavy metal levels and acute ischemic stroke. J Biomed Sci 2018;25:49.

66 Ibrahimou B, Azim SI, Sun N. Interaction between blood lead level and chronic obstructive pulmonary disease (COPD) on risk of heart attack or stroke: USA NHANES, 2013-2014. Pulm Pharmacol Ther 2019;58:101805.

67 Navas-Acien A, Tellez-Plaza M, Guallar E, et al. Blood cadmium and lead and chronic kidney disease in US adults: a joint analysis. Am J Epidemiol 2009;170:1156-64.

68 Park JB. Antihypertensive therapy and vascular protection. Korean Circ J 2000;30:1460-71.

$69 \mathrm{Yu}$ J-G, Zhou R-R, Cai G-J. From hypertension to stroke: mechanisms and potential prevention strategies. CNS Neurosci Ther 2011;17:577-84

70 Psaty BM, Furberg CD, Kuller LH, et al. Association between blood pressure level and the risk of myocardial infarction, stroke, and total mortality: the cardiovascular health study. Arch Intern Med 2001;161:1183-92.

71 Vaziri ND. Mechanisms of lead-induced hypertension and cardiovascular disease. Am J Physiol Heart Circ Physiol 2008;295:H454-65.

72 Alghasham AA, Meki A-RMA, Ismail HAS. Association of blood lead level with elevated blood pressure in hypertensive patients. Int $J$ Health Sci 2011;5:17-27.

73 Friis RH. The praeger Handbook of environmental health. California, USA: ABC-CLIO, 2012: 210

74 Nash D, Magder L, Lustberg M, et al. Blood lead, blood pressure, and hypertension in perimenopausal and postmenopausal women. JAMA 2003;289:1523-32.

75 Zheutlin AR, Hu H, Weisskopf MG, et al. Low-level cumulative lead and resistant hypertension: a prospective study of men participating in the Veterans Affairs normative aging study. J Am Heart Assoc 2018;7:e010014.

76 Lee B-K, Ahn J, Kim N-S, et al. Association of blood pressure with exposure to lead and cadmium: analysis of data from the 2008-2013 Korean National health and nutrition examination survey. Biol Trace Elem Res 2016:174:40-51.

77 Kang SY, Kim C-K. Association between lead exposure and increased risk of bronchial asthma in Korean adolescents. Allergy Asthma Respir Dis 2019;7:37-43. 